\title{
Anomalous origin of the left coronary artery from the pulmonary trunk Potential for false negative diagnosis with cross sectional echocardiography
}

\author{
P J ROBINSON, I D SULLIVAN, V KUMPENG, R H ANDERSON, F J MACARTNEY \\ From the Thoracic Unit, The Hospital for Sick Children, London
}

SUMMARY Cross sectional echocardiography can indentify anomalous origin of the left coronary artery from the pulmonary trunk. It has been suggested that identification of the left coronary artery arising from the aorta using this technique excludes the diagnosis. In three such infants the anomalous origin of the left coronary artery was identified in each by cross sectional echocardiography. In all three cases, however, an echo free linear structure apparently arising from the aorta, resembling a normal left coronary artery, was imaged. Anatomical sections in one patient, simulating cross sectional echocardiographic cuts, showed that this structure was almost certainly the transverse sinus of the pericardium. False positive cross sectional echocardiographic diagnosis of this condition is also possible because of the failure to image a normally arising left coronary artery. Thus identification of the anomalous origin of the left coronary artery from the pulmonary trunk appears to be the only reliable echocardiographic finding in this condition, and contrast cineaortography remains necessary in patients in whom the diagnosis is suspected clinically or electrocardiographically.

The diagnosis of anomalous origin of the left curonary artery from the pulmonary trunk has been made conventionally with contrast cineaortography or selective right coronary artery angiography or both. Recent studies have shown the ability of cross sectional echocardiography to identify the lesion. ${ }^{2}$ The typical features described have been pronounced dilatation and reduced contractility of the left ventricle, dilatation of the right coronary artery, absence of an aortic origin for the left coronary artery, and identification of the origin of the left coronary artery from the pulmonary trunk. It is widely believed that cross sectional echocardiographic identification of an aortic origin of the left coronary artery excludes this diagnosis.

We report three such patients recently studied with

Requests for reprints to Professor F J Macartney, Thoracic Unit, The Hospital for Sick Children, Great Ormond Street, London WCIN $3 \mathrm{JH}$.

Accepted for publication 10 May 1984 cross sectional echocardiography. In each an apparent aortic origin of the left coronary artery was readily visualised. Identification of the anomalous origin of the left coronary artery from the pulmonary trunk is probably the only reliable echocardiographic finding for diagnosing this condition.

\section{Patients and methods}

Three infants with suspected anomalous origin of the left coronary artery from the pulmonary trunk were admitted to our hospital between October and December 1983. The patients in cases 1 and 2 were female and in case 3 male. They were aged 5 weeks, 5 months, and 6 months respectively. All had presented with feeding difficulties and tachypncea. One (case 1) had an apical pansystolic murmur. The other two had no murmurs. All three had an $S_{3}$ gallop. The electrocardiogram was characteristic in each patient, showing an anterolateral infarction pattern with pathological $Q$ waves in leads $I, a V L$, and V6, and one (case 1) also had ST elevation in leads V5 and V6. Each had cardiomegaly on chest radiographs. One 
patient (case 1) had had angiocardiographic demonstration of the anomalous origin of the left coronary artery together with mild mitral regurgitation at the referring hospital. Cross sectional echocardiography was performed in all three patients followed by cardiac catheterisation and angiocardiography in two (cases 2 and 3). The machine used was an ATL (Advanced Technology Laboratories) mark 5 mechanical sector scanner with either a 5.0 or $3.0 \mathrm{MHz}$ transducer. Complete cross sectional echocardiograms were recorded, including the modified high parasternal short axis cuts previously suggested for the diagnosis of anomalous origin of the left coronary artery. ${ }^{12}$

Surgical redirection of blood flow from aorta to left coronary artery was achieved by creating an aortopulmonary window and an intrapulmonary tunnel to enclose the anomalous origin of the left coronary artery $^{34}$ in each patient. Postoperatively all three required large doses of intravenous inotropic drugs and two (cases 1 and 2) died within the first two postoperative days. Postmortem examinations were performed in both and one of the hearts was sectioned in planes to simulate parasternal short axis cross sectional echocardiographic planes. The patient in case 3 was asymptomatic when discharged and was taking digoxin, hydralazine, and diuretics.

\section{Results}

Cross sectional echocardiography showed pronounced dilatation and generalised hypokinesis of the left ventricle in all three patients. Left ventricular function was most impaired in the patient in case 2 , in whom there were also bright echoes from most of the left ventricular endocardial surface suggesting endocardial fibroelastosis.

In the patient in case 1 cross sectional echocardiography showed the anomalous left coronary artery arising from the pulmonary trunk (Fig. 1a). An echo free structure resembling a normal left coronary artery appeared, however, to arise from the aorta in the position in which a normally arising left coronary artery is usually imaged. This structure bifurcated approximately $1.5 \mathrm{~cm}$ from its apparent aortic origin (Fig. 1b). Similarly in the patient in case 2 cross sectional echocardiography identified the anomalous left coronary artery arising from the pulmonary trunk (Fig. 2a), but an echo free non-bifurcating structure also appeared to arise from the aorta in the position of a normally arising left coronary artery, although its appearance was less typical of a left coronary artery than in case 1 (Fig. 2b). Aortography showed retrograde filling of the anomalous left coronary artery via collaterals from the right coronary artery (Fig. 2c). In the patient in case 3 cross sectional echocardiography
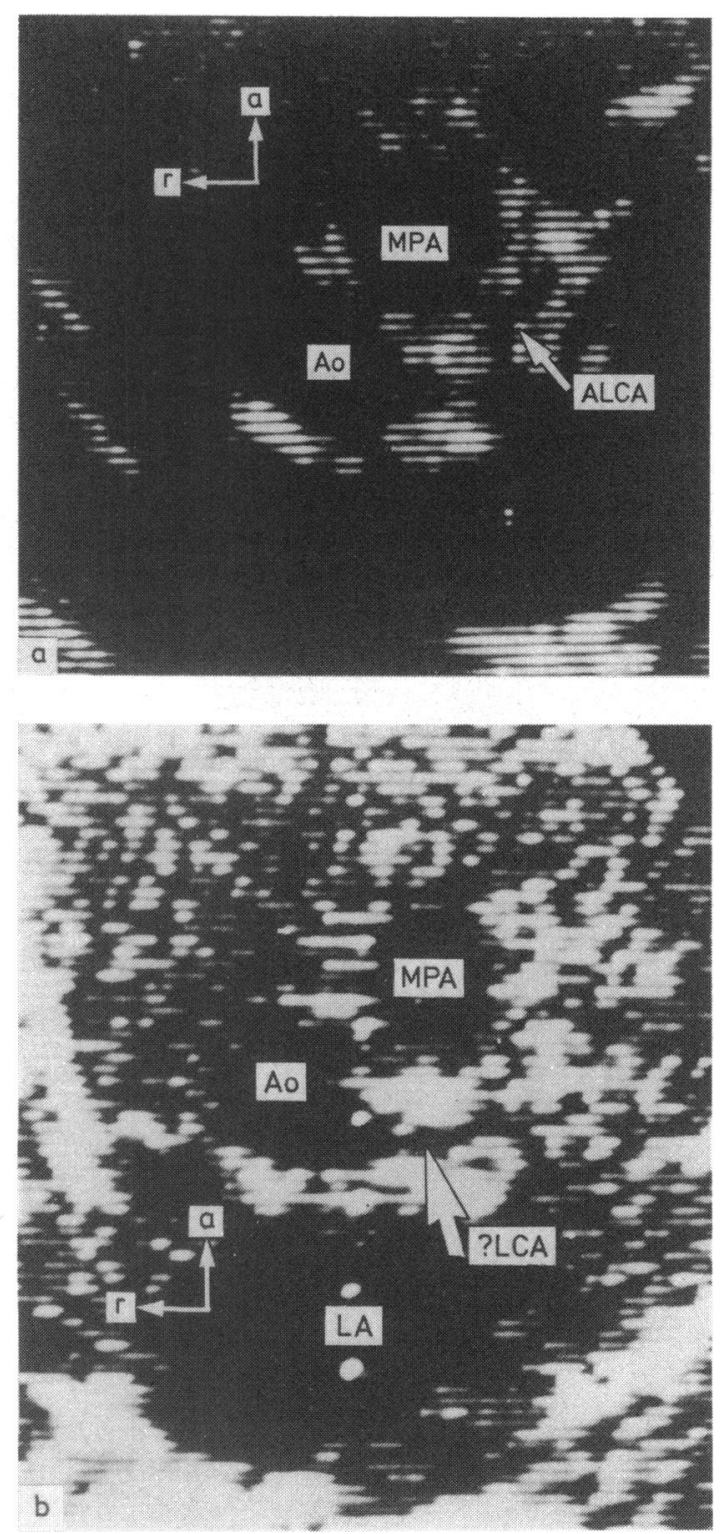

Fig. 1 Case 1-short axis cross sectional echocardiographic cuts at the level of the great arteries: (a) high parasternal view and (b) parasternal view. Ao, aorta; ALCA, anomalous left coronary artery; LA, left atrium; ?LCA, apparent left coronary artery; MPA, pulmonary trunk; $r$, right; $a$, anterior.

imaged an apparently normally bifurcating left coronary artery arising from the aorta (Fig. 3a). Its anomalous origin from the pulmonary trunk could not be demonstrated initially, but aortography confirmed the diagnosis of anomalous origin of the left coronary artery from the pulmonary artery by showing filling of 

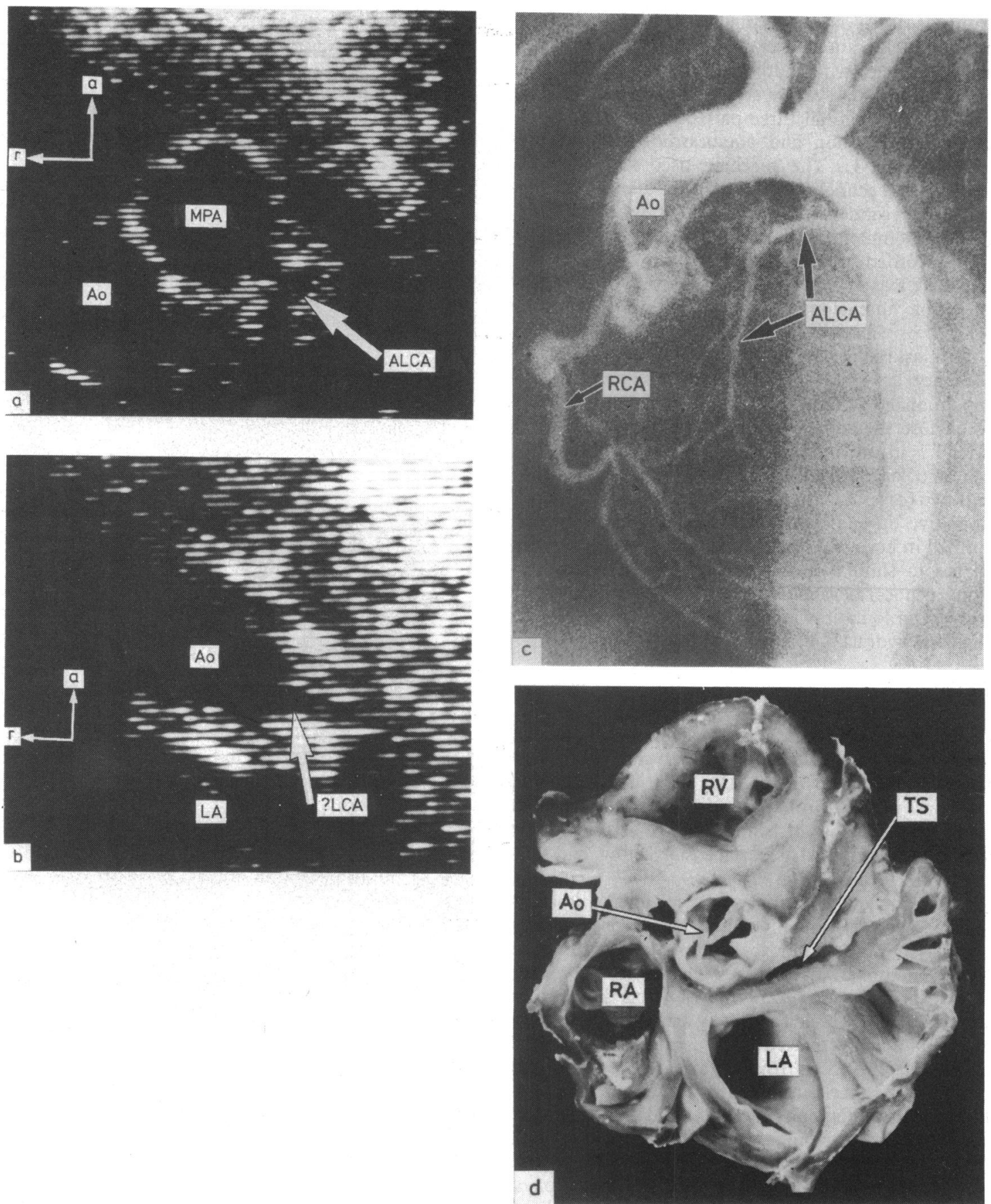

Fig. 2 Case 2-(a) and (b) short axis cross sectional echocardiographic cuts at the level of the great arteries in (a) high parasternal view and (b) parasternal view. Ao, aorta; ALCA, anomalous left coronary artery; MPA, pulmonary trunk; LA, left atrium; ?LCA, apparent left coronary artery; $a$, anterior; $r$, right. (c) Contrast aortogram (left anterior oblique) showing anterograde filling of the right coronary artery from the aorta and retrograde filling via collaterals of the anomalously arising left coronary artery. Ao, aorta; ALCA, apparent left coronary artery; RCA, right coronary artery. (d) Anatomical section to simulate a short axis cross sectional echocardiographic cut at the level of the great arteries. Ao, aorta; $L A$, left atrium; $R A$, right atrium; $R V$, right ventricle; TS, transverse sinus. 

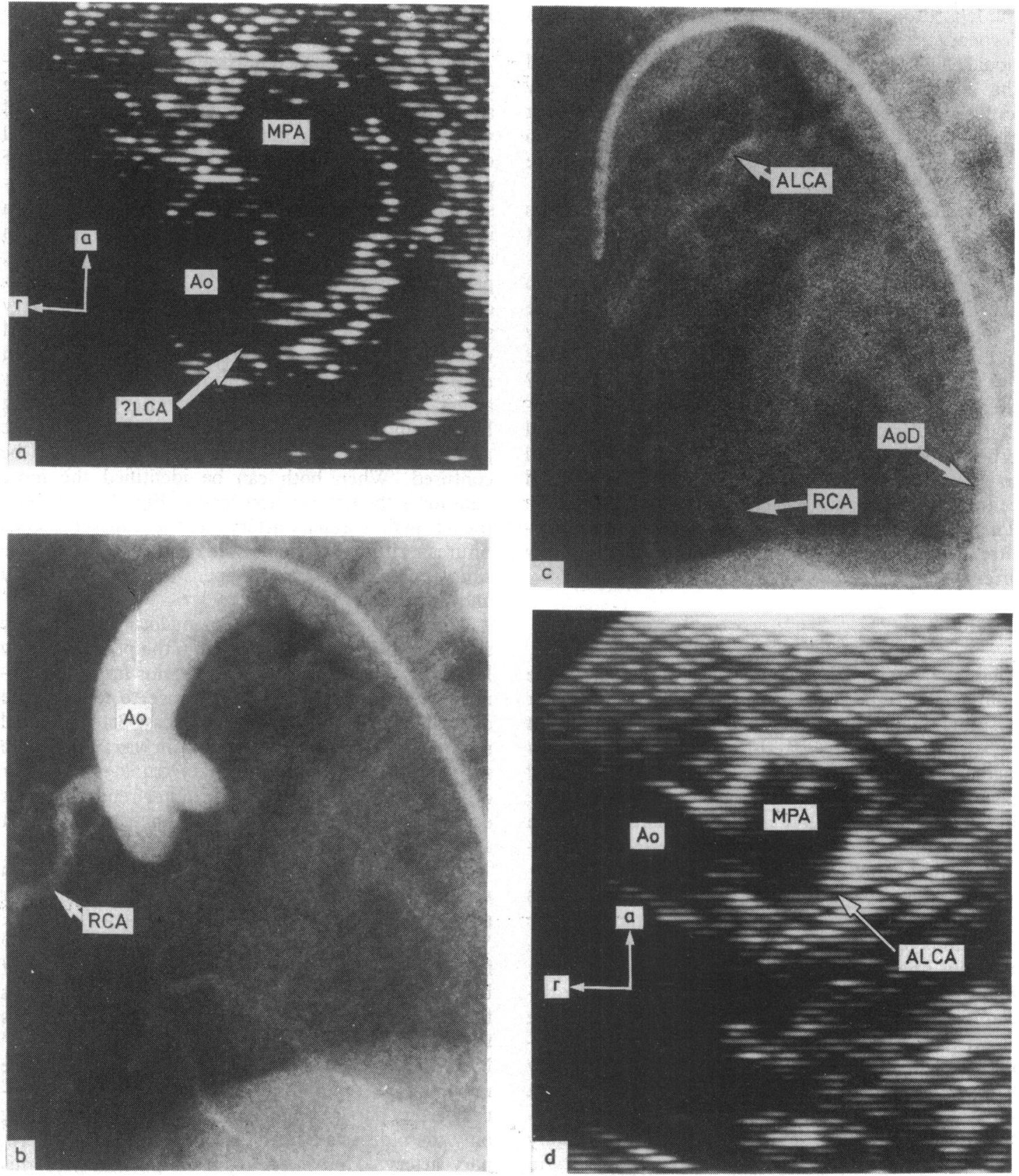

Fig. 3 Case 3-(a) parasternal short axis cross sectional echocardiographic cut at the level of the great arteries. Ao, aorta; ?LCA, apparent left coronary artery; MPA, pulmonary trunk; $a$, anterior; $r$, right. (b) Early cineangiographic frame from contrast aortogram (left anterior oblique). Ao, aorta; RCA, right coronary artery. (c) Later cineangiographic frame from an aortogram. AoD, descending aorta; $A L C A$, anomalous left coronary artery; RCA, right coronary artery. (d) High parasternal short axis cross sectional echocardiographic cut at the level of the great arteries. Ao, aorta; ALCA, anomalously arising left coronary artery; MPA, pulmonary trunk; $a$, anterior; $r$, right. 
the left coronary artery via collaterals from the right coronary artery (Figs. $3 \mathrm{~b}$ and $3 \mathrm{c}$ ). A later cross sectional echocardiogram in the patient in case 3 showed the anomalous origin of the left coronary artery (Fig. 3d) arising at a more superior and leftward point on the pulmonary trunk than in the previous two patients. None of the patients had oximetric evidence of intracardiac shunting.

Postmortem examination confirmed the diagnosis in both patients who died and showed that the left coronary artery resumed its normal course after arising from the pulmonary trunk and divided into anterior descending and circumflex branches. The sinus node artery arose from the left coronary artery in both cases. Both hearts had severe dilatation of the left ventricular cavity, and in the patient in case 2 there was severe generalised left ventricular endocardial fibroelastosis as predicted by cross sectional echocardiography. This heart (case 2) was sectioned to simulate a parasternal short axis cross sectional echocardiographic cut at the level of the great arteries. This suggested that the transverse sinus was the structure that had been mistaken for a normal left coronary artery (Fig. 2d).

\section{Discussion}

Anomalous origin of the left coronary artery from the pulmonary trunk is a rare cause of left ventricular dysfunction in infancy. Its recognition is important because of the superior results of surgical as against medical management. ${ }^{56}$ The findings on physical examination and chest radiography are non-specific, and electrocardiography, although characteristic in $80 \%$ of cases, may be similar in other forms of congestive cardiomyopathy. ${ }^{5}$

In the two previous reports of the diagnosis of this condition by cross sectional echocardiography, 12 the anomalous origin of the left coronary artery was successfully imaged in four of the seven cases studied. Those workers based the cross sectional echocardiographic diagnosis in the other three patients on the presence of a large right coronary artery and the inability to identify an aortic origin of the left coronary artery. We correctly diagnosed an anomalously arising left coronary artery on cross sectional echocardiography by imaging the origin of the left coronary artery from the posterior aspect of the pulmonary artery in two patients and incorrectly diagnosed an aortic origin of the left coronary artery in the third. A repeat study identified the anomalous origin in that patient. In all three of our patients, however, a structure which resembled a normal left coronary artery could be seen arising from the aorta. Caldwell $e a^{2}$ proposed that if the left coronary artery appeared to arise from the aorta in more than three consecutive videotape frames, as it did in each of our patients, artificial dropout was excluded and its origin was normal.

The echo free space which appeared to communicate with the aorta was almost certainly the transverse sinus of the pericardium, which is a narrow tunnel within the pericardial sac between the two pericardial cuffs encircling the great arteries anteriorly and the pulmonary and systemic veins posteriorly. ${ }^{7}$ In suprasternal long axis views of the pulmonary trunk in infants in heart failure the pericardial reflection anterior to this trunk is frequently seen (Macartney, personal observations), even when no frank pericardial effusion is present. This suggests that even a very small amount of fluid in the pericardial cavity could result in the appearance of the transverse sinus as an echo free space. Because both the left main coronary artery, continuing into its anterior descending branch, and the transverse sinus pass posterior to the pulmonary trunk it is easy to see how they can be confused. When both can be identified the more anterior is the left coronary artery (Fig. 2a), but both the left main coronary artery and the transverse sinus bifurcate, in that at the leftward end of the transverse sinus the pericardial cavity opens out both anteriorly and posteriorly.

The site of origin of the anomalous left coronary artery is variable and may be from the predominantly left facing or predominantly posterior facing pulmonary sinus of Valsalva. ${ }^{5}$ Our failure to identify the anomalous origin in the patient in case 3 at the initial study probably was because its origin was from a more superior point on the pulmonary trunk than in our other two patients and those in other reports. ${ }^{12}$ Our echocardiographic search was not concentrated in that area at the initial study.

The authors of both previous reports ${ }^{12}$ noted an unduly prominent right coronary artery in their patients, all but one of these being older than ours. When the left coronary artery arises anomalously from the pulmonary trunk the usual direction of blood flow, once pulmonary vascular resistance has fallen, is from the right coronary artery via collaterals to the left coronary and main pulmonary arteries. ${ }^{8}$ Nevertheless, while pulmonary vascular resistance remains high there is no reason why the right coronary artery should be dilated. ${ }^{8}$ Of our three patients, only the oldest had an unduly prominent right coronary artery. The oldest reported patient with this condition was aged 53 years at presentation and had a huge right coronary artery with a significant left to right shunt via extensive collaterals to the anomalous left coronary artery and main pulmonary artery. ${ }^{9}$

When cross sectional echocardiography is performed in infants transducer resolution is far more important than penetration, ${ }^{10}$ especially when small structures such as coronary arteries are imaged. This 
may explain why Caldwell $e t a^{2}$ were able to identify only six of 15 normal right coronary arteries in a group of patients with idiopathic congestive cardiomyopathy using a $2.25 \mathrm{MHz}$ transducer. In another study we were able to image the right coronary artery in all 18 patients with Kawasaki's disease, 10 of whom were aged less than 1 year. ${ }^{12}$

We believe one should be cautious in the cross sectional echocardiographic diagnosis of anomalous origin of the left coronary artery in infants. False positive diagnoses are possible owing to failùre to visualise the normal origin of the left coronary artery, and we have shown in our three patients how a false negative diagnosis may occur when an apparently normally arising left coronary artery is imaged. The right coronary artery is likely to be dilated in older patients with an anomalous left coronary artery but may be of normal calibre in infants with this condition. The only definitive cross sectional echocardiographic finding in the diagnosis of this condition is direct visualisation of the anomalous origin of the left coronary artery from the pulmonary trunk. Because of these problems as well as the need to demonstrate the presence or absence of significant collateral blood flow to plan optimal surgery, ${ }^{1011}$ contrast cineaortography remains the definitive investigation in these patients.

We thank the surgeons and physicians of the Thoracic Unit, The Hospital for Sick Children, Great Ormond Street, London, for allowing us to report details of their patients.

PJR is supported by the Wellcome Foundation and RHA and FJM are supported by the British Heart Foundation and by the Joseph Levy and Vandervell Foundations respectively.

\section{References}

1 Fisher EA, Sepehri B, Lendrum B, Luken J, Levitsky S.
Two-dimensional echocardiographic visualization of the left coronary artery in anomalous origin of the left coronary artery from the pulmonary artery. Pre- and postoperative studies. Circulation 1981; 63: 698-704.

2 Caldwell RF, Hurwitz RA, Girod DA, Weyman AE, Feigenbaum $\mathrm{H}$. Two-dimensional echocardiographic differentiation of anomalous left coronary artery from congestive cardiomyopathy. Am Heart $\mathcal{f}$ 1983; 106: 710-6.

3 Takeuchi S, Imamura H, Katsumoto K, et al. New surgical method for repair of anomalous left coronary artery from pulmonary artery. $\mathcal{F}$ Thorac Cardiovasc Surg 1979; 78: 7-11.

4 Hamilton DI, Ghosh PK, Donnelly RJ. An operation for anomalous origin of left coronary artery. $\mathrm{Br}$ Heart $\mathcal{f}$ 1979; 41: 121-4.

5 Wesselhoeft H, Fawcett JS, Johnson AL. Anomalous origin of the left coronary artery from the pulmonary trunk. Its clinical spectrum, pathology, and pathophysiology, based on a review of 140 cases with seven further cases. Circulation 1968; 38: 403-25.

6 Arciniegas E, Farooki ZQ, Hakimi M, Green EW. Management of anomalous left coronary artery from the pulmonary artery. Circulation 1980; 62 (suppl I): I-180-9.

7 Anderson RH, Becker AE. Surgical anatomy. In: Stark J, de Leval M, eds. Surgery for congenital heart defects. New York and London: Grune and Stratton, 1983: 1133.

8 Rowe RD, Freedom RM, Mehrizi A, Bloom KR, eds. The neonate with congenital heart disease. $2 \mathrm{nd}$ ed. London: W B Saunders, 1981: 428-33.

9 Alam H, Osterberger LE, Magilligan DJ Jr, Marks DS, Goldstein S. Surgical results of anomalous left coronary artery. Arch Intern Med 1983; 143: 385-6.

10 Macartney FJ. Cross sectional echocardiographic diagnosis of congenital heart disease in infants. $\mathrm{Br} \mathrm{Heart} \mathrm{f}$ 1983; 50: 501-5.

11 de Leval $M$. Congenital anomalies of sinuses of Valsalva and coronary arteries. In: Stark J, de Leval M, eds. Surgery for congenital heart defects. New York and London: Grune and Stratton, 1983: 487-500.

12 Novelli VM, Galbraith A, Robinson PJ, Smallhorn JF, Marshall WC. Cardiovascular abnormalities in Kawasaki's disease. Arch Dis Child 1984; 59: 405-9. 